\title{
ANALISIS MAKNA UNGKAPAN TO OMOU PADA NOVEL TORABERU X ROMANSU KARYA EMA KOHINATA
}

\author{
EVAT RAMADHANI FATATI, Aep Saeful Bachri', Sudjianto² \\ Departemen Pendidikan Bahasa Jepang, Fakultas Pendidikan Bahasa dan Sastra, Universitas \\ Pendidikan Indonesia \\ e3fatati@gmail.com
}

\begin{abstract}
Abstrak
Suatu ungkapan dalam bahasa Jepang apabila dicetuskan pada kondisi atau situasi tertentu akan menghasilkan makna yang berbeda. Namun kadang-kadang ungkapan yang berbeda dapat menghasilkan makna yang sama. Persamaan makna atau sinonim (ruigigo) ini juga menjadi salah satu faktor sulitnya mempelajari bahasa Jepang. Hal ini disebabkan proses penerjemahan bahasa Jepang ke dalam bahasa Indonesia dengan tidak menggunakan padanan kata yang tepat maka akan terjadi kesalahan dalam memahami apa yang dimaksud. Sehingga dalam penerjemahan bahasa Jepang perlu penggunaan ungkapan yang tepat agar maksud yang kita harapkan dapat tersampaikan. Tujuan penelitian ini adalah untuk memperjelas makna penggunaan pola kalimat $\sim$ to omou agar maksud atau apa yang ingin pengarang novel sampaikan dapat dipahami oleh pembaca. Penelitian ini menggunakan metode padan, metode ini merupakan cara menganalisis data untuk menjawab masalah yang diteliti dengan alat penentu berasal dari luar bahasa. Berdasarkan hasil analisis penelitian, terdapat bermacam-macam makna ungkapan to omou juga makna pada konjugasinya. Bentuk ini digunakan untuk mengungkapkan sesuatu/kejadian yang bersifat emosional (dari hati), dalam bentuk ini terdapat makna yang sama juga makna yang berbeda. Makna yang berbeda di pengaruhi subjek penutur, perubahan bentuk kalimat (konjungsi), objek yang dinyatakan, dan waktu penuturan.
\end{abstract}

Kata kunci : makna ungkapan, ruigigo, to omou, 


\author{
ANALYSIS MEANING OF PHRASE TO OMOU \\ ON NOUEL TORABERU X ROMANSUBY EMA KOHINATA \\ EVAT RAMADHANI FATATI, Aep Saeful Bachri', Sudjianto² \\ Departemen Pendidikan Bahasa Jepang, Fakultas Pendidikan Bahasa dan Sastra, Universitas \\ Pendidikan Indonesia \\ e3fatati@gmail.com
}

\begin{abstract}
A phrase in Japanese will have different meaning when conceived at certain situation or condition. But sometimes different phrase can make the same meaning. The same meaning or synonym (ruigigo) are also being the one of difficulty learning the Japanese. This is caused by not using proper word when change the Japanese sentence into Indonesian that will make a mistake in understanding what is meant. It is meant when changing the Japanese into Indonesian we must using proper word so it will contain meaning that we want to. This research purpose is to explaining the meaning of using to omou pattern so the intent or what the author want to can be understood by the reader. This research using unified (padan) method, this method is a way to analyze the data to answer the problem with determinants of instrument that derived from the outside of languange. Based on the analysis of research, there are various meaning on to omou pattern also on the conjugations. This phrase used to express something/events that have emotional feeling (from heart), in this phrase also have same meaning and different meaning too. A different meaning influenced by the subject, change of sentence form (conjunction), the object, and a time when it uttered.
\end{abstract}

Keyword : meaning of phrase, ruigigo, to omou 


\section{PENDAHULUAN}

Ragam bahasa dalam bentuk tulis tentu tidak berbunyi seperti layaknya ragam bahasa lisan atau bahasa yang memiliki intonasi tinggi atau rendah, sehingga tidak dapat memberi makna ekspresi dan atau kondisi lawan bicara kita (Sudjianto dan Dahidi, 2009, hlm. 210-211). Perbedaan ekspresi inilah yang mendorong kita secara tidak langsung perlu memahami ragam bahasa dalam bentuk tulis pada bahasa Jepang.

Suatu ungkapan dalam bahasa Jepang apabila dicetuskan pada kondisi atau situasi tertentu akan menghasilkan makna yang berbeda. Namun kadang-kadang ungkapan yang berbeda dapat menghasilkan makna yang sama. Persamaan makna atau sinonim (ruigigo) ini juga menjadi salah satu faktor sulitnya mempelajari bahasa Jepang. Hal ini disebabkan proses penerjemahan bahasa Jepang ke dalam bahasa Indonesia dengan tidak menggunakan padanan kata yang tepat maka akan terjadi kesalahan dalam memahami apa yang dimaksud. Sehingga dalam penerjemahan bahasa Jepang perlu penggunaan ungkapan yang tepat agar maksud yang kita harapkan dapat tersampaikan.

Salah satu ungkapan yang ingin penulis teliti adalah ungkapan $\sim$ TO OMOU yang terdapat dalam novel Toraberu $x$ Romansu karya Ema Kohinata. Novel ini menceritakan kehidupan sehari-hari beserta interaksi sosial tokoh utama terhadap lingkungannya. Interaksi tokoh utama dan karakter pendukung dalam novel ini dapat berupa pernyataan, ungkapan maksud, rencana atau keinginannya satu sama lain. Novel ini mengandung banyak pola kalimat $\sim$ to omou beserta perubahan bentuk kalimatnya.

Pada novel Toraberu $x$ Romansu, pola kalimat yang banyak digunakan adalah pola kalimat ungkapan $\sim$ to omou. Perhatikan beberapa kalimat berikut ini.

(1)「わたし、家出しようと思ってる」

決意のこもった一言を放つと、それまで長テーブルの向かい側に座り緩慢な仕草 でスプーンをロ元に運んでいた大河内明音が、ピタツとその手を止まれ (Kohinata, 2012, hlm. 7)

"Watashi, ie de shiyou to omotteru"

ketsui no komotta hitokoto o hanatsu to, sore made chō tēburu no mukaigawa ni suwari kanman'na shigusa de supūn o kuchimoto ni hakonde ita Ōkouchi Akane ga, pitatsu to sono-te o tomare

"Aku bermaksud untuk tinggal diluar rumah"

Dengan mantap aku mengatakannya, Ayah yang tengah duduk di seberang meja sedang menyuapkan sendok ke arah mulut, berhenti seketika

Kalimat di atas berpola you to omotteiru, pola ini adalah perubahan pola kalimat dasar dari ungkapan $\sim$ to omou menjadi $\sim$ you to omoimasu. Kalimat ini mengungkapkan bahwa tokoh 'saya' (watashi) berencana/bermaksud untuk tidak lagi tinggal ditempatnya saat ini (rumah), dilihat dalam narasi 'dengan mantap aku mengatakannya' ini mengandung arti bahwa tokoh 'saya' telah merencanakan cukup lama hingga menunggu waktu yang tepat untuk disampaikan kepada ayahnya. Lihat kalimat berikutnya.

（2）まさか反抗されると思っていなかったらしい父は、しばらく腕を組んだまま動か なかった (Kohinata, 2012, hlm. 18)

Masaka hankō sareru to omotte inakattarashī chichi wa, shibaraku ude o kunda mama ugokanakatta 
Ayah terdiam dengan tangan terlipat di dadanya, Ayah tampaknya tidak memikirkan bahwa aku akan menolaknya.

Kalimat ini memiliki kemiripan pola dengan kalimat sebelumnya, namun perbedaannya terdapat pada kata yang mengikuti bentuk ini to omotte inakattararashii. Kalimat ini mengungkapkan sudut pandang dari pengarang novel yang menyatakan apa yang dimaksud oleh orang ketiga (Ayah Suzuka) kepada pembaca.

Kedua bentuk tersebut sama bentuknya, namun memiliki makna yang berbeda. Oleh karena itulah alasan meneliti ungkapan tersebut.

\section{METODE PENELITIAN}

Jenis penelitian yang digunakan penulis dalam penyusunan skripsi ini adalah jenis penelitian deskriptif. Penelitian deskriptif yaitu penelitian yang dilakukan untuk menggambarkan, menjabarkan suatu fenomena yang terjadi saat ini dengan menggunakan prosedur ilmiah untuk menjawab masalah secara aktual (Sutedi, 2011, hlm. 58). Sedangkan menurut Azwar (2012, hlm. 6) berdasarkan kedalaman analisisnya penelitian deskriptif melakukan analisis hanya sampai pada taraf deskripsi, yaitu menganalisis dan menyajikan fakta secara sistematik sehingga dapat lebih mudah untuk dipahami dan disimpulkan. Berdasarkan kedua pendapat tersebut, maka penulis melakukan penelitian menggunakan jenis penelitian deskriptif.

Objek yang diteliti yaitu makna to omou yang terdapat dalam kalimat pada novel Toraberu $x$ Romansu beserta makna pada perubahan bentuknya. Objek ini dipilih berdasarkan bahwa bentuk ini memiliki pandanan kata dalam bahasa Indonesia yang berbeda-beda.

Pada studi ini, berdasarkan makna bahasa Jepang pada pola kalimat to omou, dalam bahasa Indonesia pun bentuk ini memiliki pandanan kata yang banyak. Sesuai dengan metode yang digunakan dalam penelitian, penulis menjabarkan langkahlangkah penelitian sebagai berikut :

a. Tahap pertama penulis melakukan langkah awal penelitian berupa studi literatur yaitu mengkaji atau mencari penjelasan tentang bentuk to omou dalam literatur bahasa Jepang, maupun bahasa Indonesia.

b. Berikutnya yaitu mencari kalimat $~$ to omou pada novel, lalu dkumpulkan.

c. Kemudian kalimat tersebut dianalisis.

d. Dari hasil data penelitian, kalimat to omou dideskripsikan.

e. Terakhir dalam bentuk skripsi, penulis melaporkan hasil penelitian kalimat $\sim$ to omou.

\section{HASIL DAN PEMBAHASAN}

Hasil penelitian yang didapat dari novel Toraberu $x$ Romansu adalah sebagai berikut :

\begin{tabular}{|c|c|c|c|}
\hline No & 文型 & 思考内容 & 意志 \\
\hline 1 & 「と思う」 & $\mathbf{V}$ & $\mathbf{X}$ \\
\hline 2 & 「と思います」 & $\mathbf{V}$ & $\mathbf{X}$ \\
\hline
\end{tabular}




\begin{tabular}{|c|l|c|c|}
3 & 「ようと思っています」 & X & V \\
\hline 4 & 「と思っている」 & V & X \\
\hline 5 & 「と思っていた」 & V & V \\
\hline 6 & 「と思った」 & V & V \\
\hline
\end{tabular}

Berdasarkan tabel diatas, bentuk tersebut menyatakan ungkapan isi pikiran dan maksud melakukan sesuatu atau kedua-duanya. Berikut adalah pandanan kata dalam bahasa Indonesia apabila diterjemahkan.

- Makna Kalimat Bentuk 「と思う」

Bentuk ini memiliki makna untuk menyatakan pendapat penutur dalam bentuk bahasa tulisan, Ketika diterjemahkan ke dalam bahasa Indonesia pandanan katanya yaitu 'saya rasa/pikir/kira...' (Riza, t.t).

- Makna Kalimat Bentuk 「と思います」

Bentuk ini mengungkapkan pendapat atau penilaian penutur kepada lawan bicaranya (Yoshio, 2009, hlm. 184). Ketika diterjemahkan ke dalam bahasa Indonesia pandanan katanya yaitu "saya pikir..." (Rohadi, 1997, hlm. 50).

- Makna Kalimat Bentuk「ようと思っている」

Bentuk ini memiliki makna makna menyatakan maksud/rencana penutur, dalam bahasa Indonesia memiliki arti "bermaksud akan melakukan...” (Rohadi, 1997, hlm. $55)$.

- Makna Kalimat Bentuk「と思っている」

Bentuk ini memiliki makna menyatakan pendapat penutur atau selain penutur (bukan orang pertama), Bentuk ini diartikan "pikir..." (Rohadi, 1997, hlm. 50).

- Makna Kalimat Bentuk「と思っていた」

bentuk ini digunakan untuk mengungkapkan apa yang terpikirkan oleh penutur pada saat kejadian berlangsung. Salah satunya lagi yaitu, penutur mengetahui bahwa pendapat/penilaiannya memiliki dampak jangka panjang (Yoshio, 2009, hlm.186). Dalam bahasa Indonesia diartikan "pikir..." (Rohadi, 1997, hlm. 50).

- Makna Kalimat Bentuk「と思った」

Bentuk ini digunakan untuk menyatakan apa yang telah dipikirkan penutur dalam bentuk lampau, Kemudian yang kedua yaitu penutur telah memperkiraan kejadian/hal yang telah terjadi (Yoshio, 2009, hlm.186). Arti bahasa Indonesia yaitu “telah/sudah..." (Sutedi, 2007, hlm. 27 \& 82). 


\section{KESIMPULAN}

Berdasarkan hasil penelitian sebelumnya, dapat disimpulkan bahwa makna kalimat 「と思う」 adalah lebih bersifat apa yang diungkapkan dari hati penutur secara pribadi, bentuk ini beserta bentuk-bentuk perubahannya (konjugasi) digunakan untuk mengungkapkan sesuatu atau kejadian yang bersifat emosional (menggunakan hati/perasaan) atau maksud yang realisasinya bisa terjadi atau tidak. Makna yang berbeda di pengaruhi subjek penutur, perubahan bentuk kalimat (konjungsi), objek yang dinyatakan, dan waktu penuturan.

\section{REFERENSI}

Azwar, Saifuddin. (2012). Metode Penelitian. Yogyakarta:Pustaka Pelajar.

Dahidi, Ahmad \& Sudjianto. (2009). Pengantar Linguistik Bahasa Jepang. Jakarta: Kesaint Blanc.

Kohinata, Ema. (2012). トラベル x ロマンス. Jepang:Eternity.

Riza, Miftah. (2016, 18 Januari). Grammar Bahasa Jepang : to omou, you to omou (〜と思う/〜ようと思う ). [Forum Online]. Diakses dari http://bahasajepangbersama.blogspot.co.id/2014/08/grammar-bahasa-jepang-toomou-you-to-omou.html.

Rohadi. (1997). Bentuk Ungkapan Kata Kerja yang Bervariasi Jilid 3. Jakarta:Kesaint Blank.

Sutedi, Dedi. (2007a). Nihongo No Bunpou Tata Bahasa Jepang Tingkat Dasar (Edisi Revisi). Bandung: Humaniora Utama Press.

Sutedi, Dedi. (2011b). Penelitian Pendidikan Bahasa Jepang. Bandung: Humaniora Utama Press.

Yoshio, Nitta. (2009). 現代日本語文法 4. Edisi 1. Japan:Kodansha. 


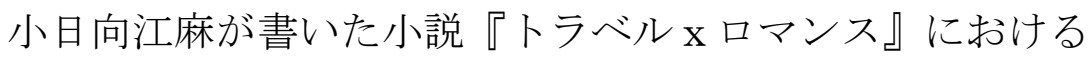

「〜と思う」表現の意味分析

1.はじめに

様々の書き言葉に話し言葉ような音がなくて、上昇調 とか下降調とか、そ して相手に表現の意味と場合がわかることができない (Sudjianto と Dahidi, 2009 : 210-211)。この別個の日本語の表現には書き言葉と話し言葉を使うとき、 わからなければならない。

特定の状況または状態で話されるとき、日本語の表現は異なる意味を持つ。 しかし、時には異なる表現で同じ意味を持たせることができる。同じ意味ま たは類義語（るいぎご）は、日本語学習者が学ぶ上で困難の一つでもある。 これは日本語からインドネシア語に翻訳するとき、間違った言葉を使って、 意味が変わる。だから、翻訳する時、正しい表現を使うことで、正しい意味 を得ることができる。

研究者は一つの表現を研究して、この表現は小日向江麻が書いた小説『ト ラベルxロマンス』に〜と思う表現の意味分析である。この小説に生活と社 交を話して、対話の社交は意志の表現とか呼びかけの表現とか希望の表現も あって、〜と思う文型と活用が多いである。

この小説『トラベル $\mathrm{x}$ ロマンス』で文型を広く使用は〜と思うである。次の 文型を見てください。

(1)「わたし、家出しようと思ってる」

決意のこもった一言を放つと、それまで長テーブルの向かい側に座り緩

慢な仕草でスプーンを口元に運んでいた大河内明音が、ピタツとその手 を止まれ (小日向, 2012:7)

その文型は「〜ようと思う」形を使って、この文型は「〜と思う」形から 「〜ようと思う」になる活用する。話し手が現在の場所 (ホーム) を動かす予 定するである。そして、次の文型を見る。

(2)まさか反抗されると思っていなかったらしい父は、しばらく腕を組んだ

まま動かなかった (小日向, $2012: 18$ )

その文型は「〜と思っていなかったらしい」形を使う。同じ形ですが、話 し手は父であって、父のことを話すである。

同じ形があって、文型の意味は違う。だから、この文型は研究者が研究の 理由することである。

2. 研究の対象及び方法

タイプの本研究を使うのは、記述的研究である。この記述的研究は現象を 科学的なプロシージャを使用して、実際の問題への対応である (Sutedi, 2011 : 58)。そして、Azwarさん (2012：6）によると、その分析の深さに基づくから、 
記述的分析研究は、説明の範囲寸ると理解しやすく寸るだけである。事実を 体系的に分析して、理解させると推論こともできる。だから、二つの意見前 から、研究者はこの記述的研究を選択する。本研究の対象は小説『トラベル xロマンス』に文の「〜と思う」の意味であって、この研究者の理由は、イン ドネシア語で文の「〜と思う」の意味が別の数である。

この研究で、「〜と思う」文型を使用する日本の言語に意味からである。こ の文型はインドネシア語に意味の活用形がいっぱいであって、だからその使 用は話し手基づいてとか表明しるとか時間を開示寸る場合である。研究で使 用される方法について、次のようである。
a. 最初のステップの研究者は文献に日本語とかインドネシア語 とか「〜と思う」についてを読む。
b. 次は小説に文の「〜と思う」を探して、この文を集める。
c. それで、この文は研究者に分析する。
d. 意味の観点から「〜と思う」文を説明する。
e. 最後は研究者が「〜と思う」文型を締結して、論文には報道を する。

3. 研究の結果

研究の結果の小説『トラベル $\mathrm{x}$ ロマンス』に以下のとおりである。

\begin{tabular}{|c|l|c|c|}
\hline No & \multicolumn{1}{|c|}{ 文型 } & 思考内容 & 意志 \\
\hline 1 & 「と思う」 & V & X \\
\hline 2 & 「と思います」 & V & X \\
\hline 3 & 「ようと思っています」 & X & V \\
\hline 4 & 「と思っている」 & V & X \\
\hline 5 & 「と思っていた」 & V & V \\
\hline 6 & 「と思った」 & V & V \\
\hline
\end{tabular}

上の表に基づいて、この文型は思考内容と意志を明らかにすることで、両 方も寸ることができる。以下は、翻訳するときに、インドネシア語で言葉を 使うことがある。

・「〜と思う」文型の意味 
この文型の意味は書き言葉で意見の話し手であって、インドネシア語に は “saya pikir/rasa/kira....”という意味である (Riza, t.t)。

・「〜と思います」文型の意味

この文型は同じ「〜と思う」の意味である。しかし、この文型は話し言 葉を使うことがある (Yoshio, 2009 ：184)。インドネシア語には “saya pikir...” という意味である (Rohadi, 1997 : 50)。

・「〜ようと思ってる」文型の意味

この文型の意味は計画の話し手または意図の話し手ことであって、イン ドネシア語には “bermaksud akan melakukan...” という意味である (Rohadi, 1997, hlm. 55)。

-「〜と思っている」文型の意味

この文型の意味は話し手以 外の思考も表すことができて、インドネシア語 には “pikir...”という意味である (Rohadi, 1997 : 50)。

・「〜と思っていた」文型の意味

この文型の意味は過去のある時点において思っていたことを表す用法で ある。それで、もう 1 つは、話してが長期にわたってもちつづけてきた 認識の妥当性について含意する用法である (Yoshio、2009：186)。イン ドネシア語には “pikir...” という意味である(Rohadi, $1997:$ 50)。

-「〜と思った」文型の意味

この文型の意味は過去のある時点に思ったことを述べる用法である。そ れで、もう 1 つは、直前に起こったことに対してそれが話し手の予想ど おりであったことをその場で確認して述べる用法である(Yoshio、2009： 186)。インドネシア語には “telah/sudah...”という意味である(Sutedi, 2007 : $27 \& 82)$ 。

4. 終わりに

先の結果から、結論付けるの研究は「と思う」文の意味が思考の話し手を 用法して、この活用形にも感情的な（心の）性質を持つ何かや出来事を表現 するために使わるや意志を表す用法であって、実現するかどうかまだ知らな いことである。異なる意味は話し手や活用形とか話す状況に影響される。

5. 参考文献

Azwar, Saifuddin. (2012). Metode Penelitian. Yogyakarta:Pustaka Pelajar. 
Dahidi, Ahmad \& Sudjianto. (2009). Pengantar Linguistik Bahasa Jepang. Jakarta: Kesaint Blanc.

Kohinata, Ema. (2012). トラベル x ロマンス. Jepang:Eternity.

Riza, Miftah. (2016, 18 Januari). Grammar Bahasa Jepang : to omou, you to omou (〜と思う/〜ようと思う ). [Forum Online]. Diakses dari http://bahasajepangbersama.blogspot.co.id/2014/08/grammar-bahasa-jepang-toomou-you-to-omou.html.

Rohadi. (1997). Bentuk Ungkapan Kata Kerja yang Bervariasi Jilid 3. Jakarta:Kesaint Blank.

Sutedi, Dedi. (2007a). Nihongo No Bunpou Tata Bahasa Jepang Tingkat Dasar (Edisi Revisi). Bandung: Humaniora Utama Press.

Sutedi, Dedi. (2011b). Penelitian Pendidikan Bahasa Jepang. Bandung: Humaniora Utama Press.

Yoshio, Nitta. (2009). 現代日本語文法 4. Edisi 1. Japan:Kodansha. 